\title{
DESIGN AND ANLYSIS OF MODIFIED HYBRID SOLAR SYSTEM USING NANO FLUIDS
}

\author{
Babu.Uppalapati \\ Assistant Professor, Department of Mechanical Engineering, \\ AITS, Tirupathi, AP, S. India.
}

\begin{abstract}
Ample literature is available on design of solar systems. However the energy conversion efficiency is about 10\%. Nearly $80 \%$ of the incoming solar energy is either reflected or absorbed as heat energy. It is expected that the efficiency of conversion is improved by using Nano-fluids in the flat plate solar collector system. An attempt is made in this paper to fabricate and to study the effect of different nano particle concentrations in water as base fluid. Nano particles of $\mathrm{TiO}_{2}$ are tried. Different particle concentrations ratios were chosen for testing. It has been observed that the thermal efficiency of solar flat plate collector has been improved by 30\% using nano fluids in the water base fluid. The major contribution of the present work is to design and analyze the effect of adding the nano particles in the water base on the thermal efficiency of the solar water heaters. It has been observed that there is nearly $30 \%$ rise in the efficiency of the solar flat plate water heaters by using nano Particles.
\end{abstract}

Keywords: Solar Systems, Heat Energy, Nano Fluids, Thermal Efficiency, Solar Flat Plate Collector.

Cite this Article: Babu.Uppalapati, Design and Anlysis of Modified Hybrid Solar System Using Nano Fluids. International Journal of Design and Manufacturing Technology 6(2), 2015, pp. 24-28.

https://iaeme.com/Home/issue/IJDMT?Volume $=6 \&$ Issue $=2$

\section{INTRODUCTION}

Nano fluids are defined as fluids with nano sized solid particles suspended in Base fluid. The suspended metallic or nonmetallic nano particles change the transport properties and heat transfer characteristics of the base fluid. Nano-fluids are the new generation heat transfer fluids for various industrial and automotive applications because of their excellent thermal performance and the word was which was coined at Argonne National Laboratory of USA by Choi in 1995 [1], which showed that the conventional liquid 
thermal performance could be remarkably improved using nano particles. Nano fluids can be used for a wide variety of engineering applications like transportation, thermal management of electronics, medical, food, defense, nuclear, space, and manufacturing of many types [2].Improving the thermal efficiency of solar flat plate water heaters is one of the key issues of energy saving and compact designs. Solar energy is widely used in applications such as electricity generation, chemical processing, and thermal heating due to its renewable and nonpolluting nature. Most solar water heating systems have two main parts: a solar collector and a storage tank. The most common collector is called a flat-plate collector but these suffer from relatively low efficiency. There are so many methods introduced to increase the efficiency of the solar water heater [3-6]. But the novel approach is to introduce the nanofluids in solar collector instead of conventional heat transfer fluids. The main reason for heat transfer enhancement is the thermal conductivity. The majority of the studies [7-13] have discussed the thermal conductivity of nano fluids, and have concluded that nano particles improve the thermal conductivity of the nano fluids.

\section{LITERATURE REVIEW}

Choi SUS etal [1], did extensive work on enhancing thermal conductivity of fluids with nanoparticles. their results very well agree with the results of other investigators. they have chosen the nano particle size in the range of 100-150 nano. They concluded that decresing the nano range below 100 has very little improvement in thermal efficiency. Wong KV etal [2], worked on Applications of nanofluids and reviewed the current and future applications of nano fluids with special reference to solar heat energy.Ho CD etal [3], worked on recycle effect on the collector efficiency improvement of doublepass sheet-and-tube solar water heaters with external recycle, and applied their results in the area of solar water heaters and concluded that the thermal efficiency of solar water heaters improved considerably. Hussain AM etal[4], did extensive work on the performance of a cylindrical solar water heater. Xiaowu W[5],did pioneering work on Energy analysis of domestic-scale solar water heaters and applied the results to commercial water heaters zones and published their results. Xuesheng $\mathrm{W}$ etal[6], made experimental investigation of a new-style double-tube heat exchanger for heating crude oil using solar hot water. Their investigations revealed that the efficiency of the heat exchanger has marginally improved when their method is used.Xie $\mathrm{H}$ etal [7], did experimental work on thermal conductivity enhancement of suspensions containing nanosized alumina particles.Xie $\mathrm{H}$ etal [8], conducted experiments to evaluate the dependence of thermal conductivity of nanoparticle-fluid mixture on the base fluid and concluded that the thermal conductivity increases with the decrease of nano range.Das SK etal [9], did experimental work on temperature dependence of thermal conductivity enhancement for nanofluids.Lee S etal [10], developed novel methods for measuring thermal conductivity of fluids containing oxide nanoparticles and applied their results in the area of solar water heaters. Lee JH etal [11], worked on estimating viscosities and thermal conductivities of aqueous nanofluids containing low volume concentrations of A1203nanoparticles.Murshed SMS etal [12], worked on Investigations of thermal conductivity and viscosity of nanofluids.Zhang X etal [13], did experimental work on Effect of thermal conductivity on thermal diffusivity and applied the results for solar water heaters. 


\section{ISSUES AND CHALLENGES RELATED TO PRESENT WORK}

- The main challenge is to fix the correct nano particle size to give the best results.

- Since the solar energy production and its utilization donot occur at the same time, storing the solar energy when it is not required needs proper consideration.

- All efforts have to be taken to improve the efficiency of the solar water heaters.

\section{SCOPE AND OBJECTIVES OF PRESENT WORK}

The scope of the present work is to design for, nano-particle size and the geometry of the solar water heater to satisfy the objective of improving the thermal efficiency of solar flat plate water heaters.

\section{PRESENT WORK}

The present work is split into the following modules

- Identification of the area and timing for conducting experiments.

- Choosing the material for nano particles to be added in the water nano fluid.

- Fabrication of the conventional standard solar flat plate water heater.

- Conducting experiments using different nano particle size $(50,100,150 \mathrm{~nm})$, in the water nano fluid and noting down the rise in temperature, keeping other parameters fixed.

- Analyzing the results.

\section{RESULTS AND DISCUSSIONS}

- The specifications of the flat plate solar water heater along with the experimental setup is shown below

Table 1 specifications of the flat plate solar water heater

\begin{tabular}{|c|c|c|}
\hline Specification & Dimension & \multirow{2}{*}{ Copper } \\
\hline Absorber Plate Length & $0.5 \mathrm{~m}$ & \multirow{2}{*}{ Copper } \\
\hline Absorber Plate Width & $0.2 \mathrm{~m}$ & \\
\hline Absorber Plate Thickness & $0.001 \mathrm{~m}$ & Glass \\
\hline $\begin{array}{c}\text { Inside Diameter Of Riser } \\
\text { Tube }\end{array}$ & $0.003 \mathrm{~m}$ & MDF \\
\hline $\begin{array}{c}\text { Outside Diameter Of Riser } \\
\text { Tube }\end{array}$ & $0.004 \mathrm{~m}$ & Rockwool \\
\hline Cover Thickness & $0.005 \mathrm{~m}$ & \\
\hline Edges Thickness & $0.016 \mathrm{~m}$ & \\
\hline Back Thickness & $0.05 \mathrm{~m}$ & \\
\hline The Tilt Angle & $55^{\circ}$ & \\
\hline $\begin{array}{c}\text { The Tube Welded To Plate } \\
\text { All Over }\end{array}$ & & \\
\hline $\begin{array}{c}\text { Absorber Plate Painted By } \\
\text { Black Matte }\end{array}$ & & \\
\hline
\end{tabular}




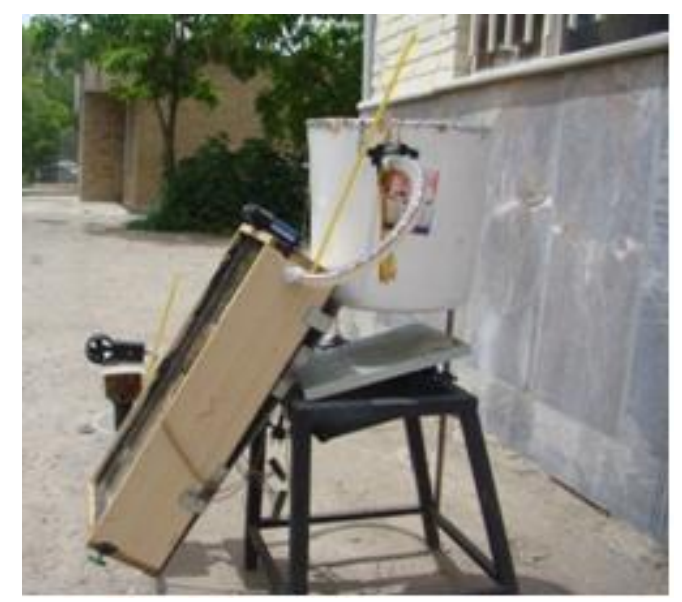

Figure 1 The experimental flat plate solar collector

- So far, many researchers have proven that the nanofluids enhance the heat transfer coefficient as comPparing with conventional fluid. In this research, to evaluate the effect of nanofluid on solar collector efficiency, three levels of $\mathrm{TiO} 2$ nano particles concentrations (without using surfactants) were examined and the results were compared with those of water. It has been concluded that the addition of nano particles in the water medium has improved the thermal efficiency by nearly $30 \%$.

\section{CONCLUSIONS}

The major contribution of the present work is to design and analyse the effect of adding the nano particles in the water base on the thermal efficiency of the solar water heaters. It has been observed that there is nearly $30 \%$ rise in the efficiency of the solar flat plate water heaters by using Nano Particles

\section{REFERENCAES}

[1] Choi SUS. Enhancing thermal conductivity of fluids with nanoparticles. ASME FED-Vol. 231/MD-Vol. 66 1995:99-103.

[2] Wong KV, Leon OD. Applications of nanofluids: current and future. Advances in Mechanical Engineering 2010(ID 519659):pp 11.

[3] Ho CD, Chen TC. The recycle effect on the collector efficiency improvement of double-pass sheet-and-tube solar water heaters with external recycle. Renew Energy 2006; 31(7):953-970.

[4] Hussain AM. The performance of a cylindrical solar water heater. Renew Energy 2006; 31(11):1751-1763.

[5] Xiaowu W, Hua B. Energy analysis of domestic-scale solar water heaters. Renew Sustain Energy Rev 2005; 9(6):638-645.

[6] Xuesheng W, Ruzhu W, Jingyi W. Experimental investigation of a newstyle double-tube heat exchanger for heating crude oil using solar hot water. In: Appl Therm Eng; 2005. p. 1753-1763.

[7] Xie H, Wang J, Xi T, Ai F. Thermal conductivity enhancement of suspensions containing nanosized alumina particles. Int. J. Appl. phys 2002; 91:4568-4572. 
[8] Xie H, Wang J, Xi T, Ai F. Dependence of thermal conductivity of nanoparticle-fluid mixture on the base fluid. J. Mater. Sci. Lett. 2002; 21:1469-1471.

[9] Das SK, Putta N, Thiesen P, Roetzel W. Temperature dependence of thermal conductivity enhancement for nanofluids. J. Heat Transfer 2003; 125:56774.

[10] Lee S, Choi SUS, Li S, Eastman JA. Measuring thermal conductivity of fluids containing oxide nanoparticles. Trans. ASME J. Heat Transfer 1999; 121:280-289.

[11] Lee JH, Hwang KS, Jang SP, et al. Effective viscosities and thermal conductivities of aqueous nanofluids containing low volume concentrations of $\mathrm{Al}_{2} \mathrm{O}_{3}$ nanoparticles. Int. J. Heat Mass Transfer 2007; 51:2651-2656.

[12] Murshed SMS, Leong KC, Yang C. Investigations of thermal conductivity and viscosity of nanofluids. Int. J. Thermal Sci. 2008; 47:560-568.

[13] Zhang X, H. G, Fujii M. Effective thermal conductivity and thermal diffusivity. Exp. Thermal Fluid Sci. 2007; 31:593-599. 